\title{
KEPADATAN STOK IKAN DEMERSAL MENGGUNAKAN ALAT TANGKAP DOGOL DI KABUPATEN PANGANDARAN
}

\section{Demersal Fish Stock Density Using Mini Bottom Trawl in Pangandaran District}

Oleh:

\author{
Lantun Paradhita Dewanti ${ }^{1}$, Haidar Fathurrahman ${ }^{1}$, Alexander Khan ${ }^{1}$, Izza \\ Mahdiana Apriliani ${ }^{1}$, Heti Herawati ${ }^{1}$ \\ ${ }^{1}$ Fakultas Perikanan dan Ilmu Kelautan, Universitas Padjadjaran, Indonesia \\ Korespondensi: lantun.paradhita@unpad.ac.id
}

\begin{abstract}
ABSTRAK
Keberadaan dogol dianggap berkontribusi terhadap menurunnya kondisi sumberdaya perikanan di Pangandaran, khususnya ikan demersal. Optimalisasi pemanfaatan sumberdaya ikan dapat dilakukan apabila adanya ketersediaan dan distribusi sumberdaya telah diketahui dengan baik sehingga langkah kebijakan eksploitasi dapat dilakukan dengan tepat tanpa membahayakan kelestariannya. Tujuan dari riset ini adalah untuk menganalisis laju tangkap dan kepadatan stok ikan demersal berdasarkan luas area sapuan alat tangkap dogol yang dioperasikan di perairan Kabupaten Pangandaran, Jawa Barat. Riset dilaksakan mulai bulan Agustus 2018-Juli 2019 di wilayah timur perairan Pangandaran. Pengambilan sampel dilakukan di tiga stasiun (Desa Sagara Anakan, Bagolo, dan Babakan) dengan masing-masing 8 kali ulangan. Metode yang digunakan adalah metode survei dengan sampel ikan demersal diambil secara langsung dengan metode sapuan wilayah menggunakan alat tangkap dogol. Hasil tangkapan utama alat tangkap dogol di Pangandaran terdiri dari udang dogol (Metapenaeus ensis) dengan presentase 2\%, udang rebon (Acetes indicus) dengan presentase 81\%, dan udang krosok (Parapenaopsis sp.) dengan presentase $14 \%$. Kondisi oseanografis di wilayah penelitian memiliki substrat lumpur dan lumpur berpasir dengan kedalaman berkisar antara 8-120 meter. Hasil riset menunjukkan alat tangkap dogol yang digunakan di stasiun 3 memiliki nilai laju tangkap terbesar yaitu sebesar 21,08 kg/jam, sedangkan kepadatan stok tertinggi ada pada stasiun 2 dengan nilai densitas $423,7 \mathrm{~kg} / \mathrm{km}^{2}$.
\end{abstract}

Kata kunci: dogol, ikan demersal, laju tangkap, kepadatan stok

\section{ABSTRACT}

The existence of mini bottom trawl is considered to contribute to the declining condition of fisheries resources in Pangandaran, especially demersal fish. Utilization of fish resources can optimally used if the stocks and distribution of fish resources are known with properly, so so that the policy steps to utilize fish resources can be done appropriately without endangering their sustainability. The purpose of this research is to analyze the catch rate and density of demersal fish stocks based on the area of the sweeping mini bottom trawl which have landed in Pangandaran, West Java. Research was carried out starting in August 2018-July 2019 in the eastern region of Pangandaran waters. Sampling was carried out in 3 stations (Desa Sagara Anakan, Bagolo, and Babakan) with 8 replications each. The method used is a survey method with demersal fish samples taken directly with area sweep method using mini bottom trawl. The main catches of mini bottom trawl in Pangandaran consist of Metapenaeus ensis with a percentage of $2 \%$, Acetes indicus with a percentage of $81 \%$, and Parapenaopsis sp. With a percentage of 14\%. Oceanographic conditions in the study area have mud and sandy mud substrates with depths ranging from 8-120 meters. The results showed that the dogol 
gear used at station 3 had the largest catch rate, which was $21.08 \mathrm{~kg} /$ hour, while the highest stock density was at station 2 with a density value of $423.7 \mathrm{~kg} / \mathrm{km}^{2}$.

Key words: catch rate, demersal fish, density, mini bottom trawl

\section{PENDAHULUAN}

Wilayah peraian di Kabupaten Pangandaran termasuk dalam zona Wilayah Pengelolaan Perikanan (WPP) 573 yang meliputi perairan Samudera Hindia sebelah selatan Jawa hingga sebelah selatan Pulau Nusakambangan. Selain sektor pariwisata, potensi sumberdaya perikanan juga menyumbangkan kontribusi yang cukup besar bagi perekonomian dan pendapatan asli daerah Kabupaten Pangandaran (Nurhayati, 2013). Kegiatan perikanan tangkap di Kabupaten Pangandaran disokong oleh armada kapal motor tempel yang menggunakan katir (cadik) berukuran $<5$ GT. Alat tangkap yang dioperasikan oleh nelayan Pangandaran diantaranya pancing rawai, jaring arad (pukat pantai), gillnet, trammel net, dan dogol (Fauzy, 2009). Salah satu alat yang beroperasi di Pangandaran adalah jaring dogol atau mini bottom trawl. Alat tangkap ini dioperasikan untuk dapat menangkap berbagai jenis ikan demersal.

Peraturan Menteri Kelautan dan Perikanan Nomor 2 tahun 2015 mengenai pelarangan pengoperasian pukat hela dan pukat tarik menyebabkan alat tangkap dogol dilarang pengoperasiannya karena jenis alat tangkap ini termasuk ke dalam pukat tarik berkapal (boat or vessel seines). Alat tangkap dogol dinilai memiliki selektivitas yang rendah dan berpotensi merusak area sapuan yang dilaluinya (Fahmi \& Yonvitner 2016). Atas dasar inilah diberlakukan larangan penggunaan alat tangkap tersebut karena dinilai dapat menyebabkan menurunnya stok dan keberagaman sumberdaya ikan dan bisa merusak ekosistem sebagai upaya mewujudkan pemanfaatan sumber daya ikan yang bertanggung jawab, optimal dan berkelanjutan (Hakim 2016).

Ikan demersal merupakan hasil tangkapan yang biasa tertangkap oleh alat tangkap dogol. Umumnya, ikan demersal menyukai habitat dengan substrat lumpur atau lumpur berpasir (Cahya et al. 2016). Salah satu alasan diberlakukannya pelarangan alat tangkap dogol adalah penggunaannya yang dianggap mengakibatkan menurunnya sumberdaya ikan, sehingga sumberdaya ikan demersal di perairan Pangandaran memerlukan pengelolaan yang rasional agar pemanfaatannya dapat lestari dan berkelanjutan. Salah satu unsur penting yang diperlukan untuk mendukung upaya tersebut adalah tersedianya data dan informasi tentang indeks biodiversitas ikan. Tujuan dari riset ini adalah untuk menganalisis laju tangkap dan kepadatan stok ikan demersal berdasarkan luas area sapuan alat tangkap dogol yang dioperasikan di perairan Kabupaten Pangandaran, Jawa Barat sebagai dasar pengelolaan perikanan tangkap yang berkelanjutan dan ramah lingkungan.

\section{METODE PENELITIAN}

Penelitian dilaksanakan mulai bulan Agustus 2018-Januari 2019 di Perairan Kabupaten Pangandaran, Jawa Barat. Sampel didapat dari 3 stasiun yang berbeda dengan 8 kali ulangan pada tiap stasiunnya. Lokasi stasiun ditentukan dengan alasan agar sampel yang diambil dapat mewakili seluruh wilayah pantai timur, yaitu barat, tengah, dan timur dengan rincian sebagai berikut (Gambar 1):


Kecamatan Kalipucang)

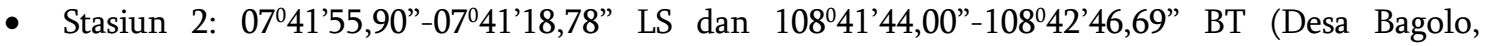
Kecamatan Kalipucang)

- Stasiun 3: $07^{0} 43^{\prime} 38,46^{\prime \prime}-07^{0} 44^{\prime} 43,09^{\prime \prime}$ LS dan 10841'19,41'-108 $41^{\prime} 19,58^{\prime \prime}$ BT (Desa Babakan, Kecamatan Pangandaran) 

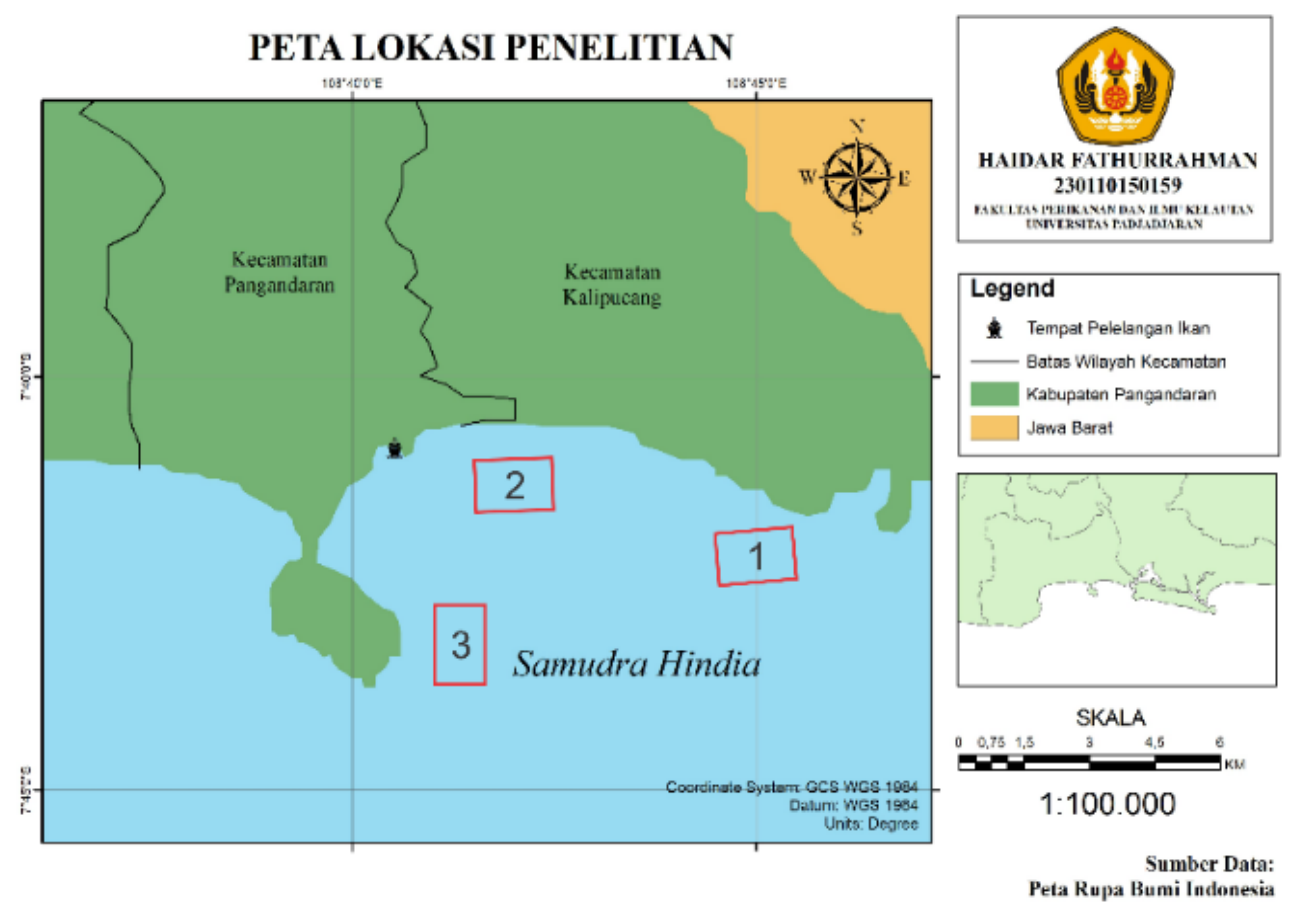

Gambar 1 Peta lokasi penelitian

Alat tangkap dogol dengan target spesies berupa ikan demersal. Selama pelaksanaan penelitian menggunakan 3 kapal dengan spesifikasi ukuran jaring yang berbeda-beda (Tabel 1). Perbedaan ukuran jaring berpengaruh terhadap luasan area sapuan alat tangkap ketika dioperasikan sehingga berpengaruh pula terhadap hasil tangkapan. Ukuran mata jaring pada bagian kantong tergolong kecil sehingga memiliki by-catch yang tinggi serta menangkap target dengan ukuran yang tidak layak tangkap.

Tabel 1 Karakteristik alat tangkap dogol

\begin{tabular}{cccccc}
\hline Stasiun & $\begin{array}{c}\text { Panjang tali } \\
\text { selambar }(\mathrm{m})\end{array}$ & $\begin{array}{c}\text { Panjang tali } \\
\text { ris atas }(\mathrm{m})\end{array}$ & $\begin{array}{c}\text { Mesh size } \\
\text { kantong (inch) }\end{array}$ & $\begin{array}{c}\text { Lebar sayap } \\
(\mathrm{m})\end{array}$ & Bahan \\
\hline 1 & 200 & 37,5 & 0,5 & 18,75 & Polyethylene \\
2 & 200 & 40,5 & 0,5 & 30,37 & Polyethylene \\
3 & 200 & 45 & 0,5 & 33,7 & Polyethylene \\
\hline
\end{tabular}

Data yang digunakan dalam penelitian ini meliputi data primer dan sekunder. Data primer terdiri dari ikan demersal yang tertangkap oleh alat tangkap dogol dan keragaan alat tangkap dogol, sedangkan data sekunder meliputi citra satelit kedalaman perairan, karakteristik substrat perairan, dan data statistik perikanan tangkap Kabupaten Pangandaran. Identifikasi ikan dilakukan di Tempat Pelelangan Ikan Pangandaran (Jongor Batu) dengan mengidentifikasi karakteristik morfologi ikan yang tertangkap pada waktu penelitian. Identifikasi yang dilakukan terhadap alat tangkap dogol meliputi nama kapal, nama pemilik kapal, panjang tali ris atas pada jaring, panjang tali selambar, lama penarikan jaring, kecepatan penarikan jaring, dan jumlah tebar jaring setiap trip. Parameter oseanografi yang diamati antara lain suhu permukaan laut dan informasi kedalaman yang diidentfikasi dengan metode penginderaan jauh, dan karakteristik substrat dasar perairan yang diidentifikasi dengan metode studi literatur. 
Area sapuan jaring dogol adalah sebagai berikut (Pauly1980):

$$
A=\frac{\left(\frac{2}{3}\right) L \cdot v(1,85 \times 0,001)}{t}
$$

Keterangan:

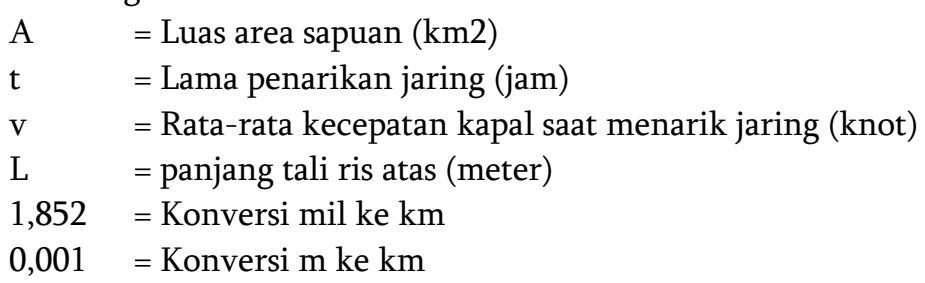

Kepadatan tangkapan per jam hasil tarikan jaring dogol dihitung dengan (Spare and Vennema 1999; Sumiono 2017; Dewanti 2018):

$$
\text { Laju tangkap }=\frac{\text { Bobot }}{\mathrm{t}}
$$

Keterangan:

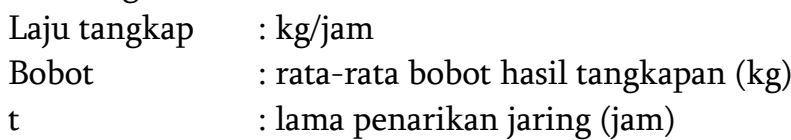

Metode swept area digunakan untuk melakukan perhitungan kepadatan stok dengan memperhitungkan berdasarkan luas areal yang dilalui, rata-rata kecepatan kapal saat menarik jaring, lebar bukaan mulut jaring, dan hasil tangkapan Sparre \& Venema (1998) sebagai berikut:

$$
\mathrm{D}=\left(\frac{1}{A}\right) x\left(\frac{e}{f}\right)
$$

Keterangan:

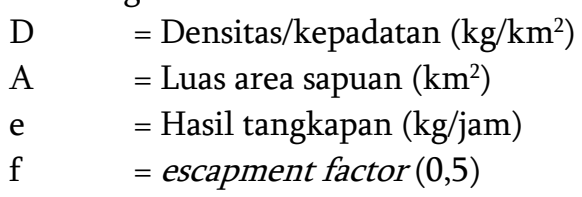

\section{HASIL DAN PEMBAHASAN}

Kedalaman laut memberikan informasi penting mengenai apa yang bisa dimanfaatkan dari laut tersebut. Pengetahuan mengenai kedalaman laut biasanya digunakan berkaitan dengan sistem navigasi pelayaran, namun selain itu kedalaman laut juga dapat memberi informasi mengenai sebaran makhluk hidup yang tinggal di dalamnya (Pambuko et al. 2013). Perairan laut Pangandaran berhadapan langsung dengan Samudera Hindia, sehingga sangat bepengaruh terhadap kedalaman perairannya. Nelayan dengan alat tangkap dogol melakukan aktivitas penangkapan dengan kapal motor tempel yang berukuran <5 GT sehingga wilayah penangkapannya terbatas dan tidak terlalu jauh dari pelabuhan. Hal tersebut menunjukkan bahwa daerah pengoperasian alat tangkap dogol di Kabupaten Pangandaran berada pada perairan dengan kedalaman sekitar 10-40 meter. Menurut Purbayanti et. al. (2005) daerah pemijahan (spawning ground), tempat ikan mencari makan (feeding ground) dan pemeliharaan (nursery ground) terdapat banyak sumberdaya ikan karena merupakan perairan yang dangkal. Hal ini terbukti dengan banyaknya jenis-jenis ikan muda yang ikut tertangkap oleh alat tangkap dogol di Pangandaran yang tentu dapat mengancam kelestarian sumberdaya ikan demersal di Kabupaten Pangandaran. Berdasarkan data kedalaman yang didapat dari topex.ucsd.edu dan diolah menggunakan aplikasi Microsoft Excel dan Surfer, kedalaman perairan wilayah penelitian berkisar antara 8-120 meter (Gambar 2). 


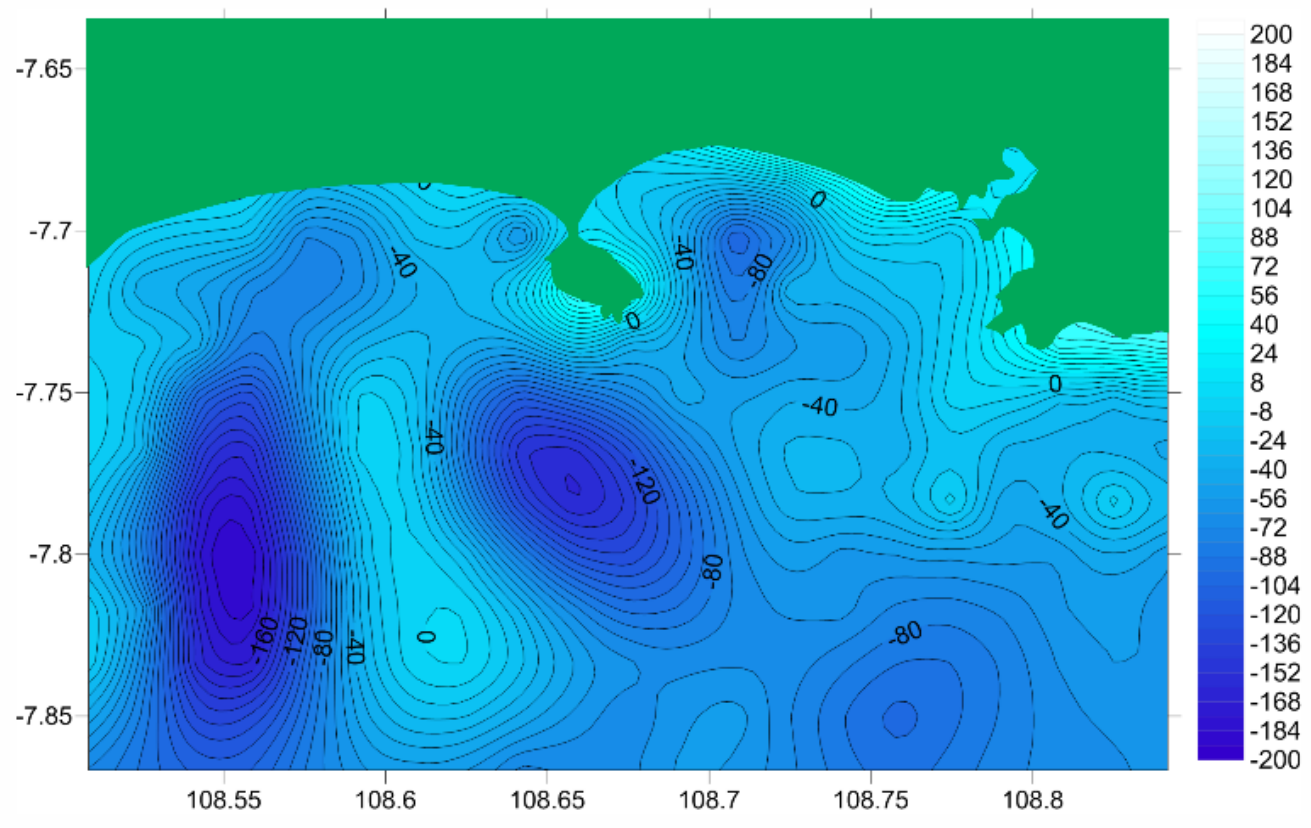

Gambar 2. Profil kedalaman wilayah penelitian (sumber: topex.ucsd.edu)

Tiap stasiun pengambilan data memiliki profil kedalaman yang berbeda. stasiun 3 memiliki wilayah dengan kedalaman yang paling dalam yaitu berkisar antara 24-120 meter, sementara stasiun 1 dan 2 memiliki kedalaman yang sama yaitu berkisar antara 8-40 meter (Tabel 2). Profil kedalaman wilayah penelitian menunjukkan bahwa ikan demersal di Kabupaten Pangandaran mendiami wilayah dengan kedalaman 8-120 meter. Hal tersebut sesuai dengan riset yang menyatakan bahwa demersal banyak ditemukan pada kedalaman 20-40 m. Biota yang mendiami dasar perairan dengan profil kedalaman kurang dari 100 meter didominasi oleh berbagai jenis benthos terutama krustasea dan ikan famil Sciaenidae (ikan tigawaja) dan Trichiuridae (ikan layur) yang merupakan kelompok ikan demersal (Hidayat dan Nurulludin 2017).

Tabel 2 Profil kedalaman tiap stasiun pengambilan data

\begin{tabular}{cc}
\hline Stasiun & Kedalaman $(\mathrm{m})$ \\
\hline 1 & $8-40$ \\
2 & $8-40$ \\
3 & $24-120$ \\
\hline
\end{tabular}

Ikan demersal merupakan ikan yang hidup di dasar perairan dan mendiami beberapa wilayah dengan karakteristik substrat yang berbeda. Substrat dasar perairan memiliki peranan sebagai penyimpan unsur hara yang berasal dari laut dan yang berasal dari daratan melalui berbagai proses. Unsur hara yang berada di substrat dimanfaatkan oleh mikrofauna sebagai pengurai menjadi bahan organik yang kemudian digunakan sebagai bahan makanan bagi organisme lain. Kebiasaan makan ikan demersal yang memperoleh sumber makanan dari substrat maka keberadan organisme ini bergantung kepada jenis substrat sebagai faktor pembatas.

Karakteristik wilayah penelitian memiliki dasar perairan yang landai serta merupakan daerah perairan pesisir dengan substrat berlumpur. Jenis substrat tersebut merupakan habitat bagi berbagai jenis ikan demersal (Dewanti et al. 2018). Tipe substrat dapat mempengaruhi kehidupan organisme yang hidup di dasar perairan. Ikan-ikan yang termasuk ikan demersal umumnya dapat hidup dengan baik pada perairan yang bersubstrat lumpur atau lumpur berpasir (Pujiyati et al 2017). Umumnya, ikan demersal mengelompok pada perairan yang bersubstrat lumpur atau lumpur berpasir (Akbar 2013). 
Perairan selatan Jawa merupakan perairan yang dasar perairannya adalah datar dan cenderung berlumpur.

Komposisi hasil tangkapan alat tangkap dogol didominasi oleh beberapa jenis udang, seperti udang rebon (Acetes indicus), udang krosok (Parapenaopsis sp.), dan udang dogol (Metapenaeus ensis). Hasil tangkapan sampingan alat tangkap dogol terdiri dari beberapa jenis ikan demersal, seperti ikan layur, pepetek, ikan sebelah, dan ikan montok. Secara garis besar, hasil tangkapan alat tangkap dogol terdiri dari 18 spesies yang berasal dari 15 famili (Tabel 3).

Tabel 3 Komposisi jenis tiap stasiun

\begin{tabular}{lccc}
\hline \multicolumn{1}{c}{ Parameter } & Stasiun 1 & Stasiun 2 & Stasiun 3 \\
\hline Jumlah family & 15 & 14 & 13 \\
Jumlah spesies & 18 & 17 & 17 \\
Jumlah individu & 4.582 & 6.761 & 20.517 \\
Total bobot $(\mathrm{kg})$ & 25,36 & 33,86 & 50,6 \\
Laju tangkap $(\mathrm{kg} / \mathrm{jam})$ & 10,568 & 10,159 & 21,083 \\
\hline
\end{tabular}

Ikan demersal pada lokasi sampling selama penelitian berlangsung, komposisinya tidak jauh berbeda pada tiap stasiunnya. Hal ini membuktikan bahwa perairan Pangandaran merupakan satu komunitas yang didukung dengan perilaku ikan demersal yang mempunyai aktifitas gerak rendah dan beruaya tidak terlalu jauh dari garis pantai dengan kedalaman yang tidak jauh berbeda.

Sampel utama penelitian diambil menggunakan alat tangkap dogol dengan metode swept area. Alat tangkap dogol di Pangandaran merupakan alat tangkap yang khusus digunakan untuk menangkap berbagai jenis udang, seperti udang dogol, udang rebon, udang krosok, dan lain sebagainya sehingga hasil tangkapan utama alat tangkap ini adalah beberapa jenis udang tersebut. Berdasarkan komposisi jenisnya, hasil tangkapan alat ini didominasi oleh jenis udang-udangan.

Data komposisi jenis ikan demersal diambil pada bulan Agustus 2018 (musim timur) dan bulan Januari 2019 (musim barat). Berdasarkan data yang didapat, hasil tangkapan yang tertangkap oleh alat tangkap dogol pada bulan Agustus 2018 lebih banyak jika dibandingkan pada bulan Januari 2019 (Tabel 4). Hal ini menunjukan bahwa musim berpengaruh terhadap kegiatan penangkapan ikan di Kabupaten Pangandaran.

Tabel 4 Perbandingan bobot hasil tangkapan

\begin{tabular}{ccc}
\hline \multirow{2}{*}{ Stasiun } & \multicolumn{2}{c}{ Bobot rata-rata hasil tangkapan $(\mathrm{kg})$} \\
\cline { 2 - 3 } & Agustus & Januari \\
\hline 1 & 31,95 & 18,77 \\
2 & 39,67 & 28,05 \\
3 & 81,75 & 19,45 \\
\hline
\end{tabular}

Kegiatan penangkapan ikan sebagian besar dilakukan pada musim timur, sedangkan pada musim barat nelayan hanya melakukan aktivitas penangkapan dalam intensitas yang lebih sedikit karena besarnya gelombang laut dan sedikitnya hasil tangkapan. Hasil tangkapan pada musim barat cenderung lebih sedikit jika dibandingkan dengan hasil tangkapan pada musim timur yang terjadi pada bulan Juni sampai dengan Agustus. Perbedaan banyaknya hasil tangkapan ini menunjukkan adanya perbedaan pertumbuhan ikan yang nyata antara musim barat dan musim timur.

Pemanfaatan sumber daya ikan dapat dilakukan secara optimal apabila sediaan (stok) dan sebaran sumber daya ikan diketahui secara pasti sehingga langkah kebijakan eksploitasi dapat dilakukan dengan tepat tanpa membahayakan kelestariannya (Priatna \& Wijopriono 2011). Menurut Firdaus (2010), laju tangkap menggambarkan kemampuan tangkap suatu alat tangkap per upaya penangkapan. Kemampuan tangkap suatu alat tangkap mewakili hasil tangkapan dalam satuan gram/kilogram/ton. Upaya penangkapan yang menjadi bagian dalam analisis laju tangkap adalah upaya penangkapan seperti 
lama tarikan jaring, durasi pengangkatan dan durasi panen yang dikonversi dalam satuan waktu. Kepadatan stok dihitung menggunakan metode swept area berdasarkan luas area sapuan yang dilalui, kecepatan kapal saat melakukan towing, lebar bukaan jaring, dan nilai laju tangkap (Sparre dan Venema 1998).

Alat tangkap dogol yang digunakan di stasiun 3 memiliki nilai laju tangkap terbesar yaitu sebesar $21,08 \mathrm{~kg} / \mathrm{jam}$, sedangkan nilai laju tangkap terendah terdapat pada alat tangkap dogol yang digunakan di stasiun 2 (Tabel 5). Ditinjau dari dimensi ukuran alat tangkap, hasil tersebut dikarenakan alat tangkap yang digunakan pada stasiun 3 memiliki dimensi ukuran paling besar jika dibandingkan dengan alat tangkap yang digunakan pada stasiun lainnya, sehingga memiliki luasan area sapuan yang lebih luas dan laju tangkapnya pun lebih besar.

Tabel 5 Laju tangkap dan kepadatan stok ikan demersal

\begin{tabular}{lcccc}
\hline \multirow{2}{*}{ Parameter } & \multicolumn{3}{c}{ Stasiun } & Rata-rata \\
\cline { 2 - 5 } & 1 & 2 & 3 & \\
\hline Laju tangkap $(\mathrm{kg} / \mathrm{jam})$ & 10,57 & 10,16 & 21,08 & 13,94 \\
Kepadatan stok $\left(\mathrm{kg} / \mathrm{km}^{2}\right)$ & 380,82 & 423,70 & 281,39 & 361,97 \\
\hline
\end{tabular}

Kepadatan stok tertinggi ada pada stasiun 2 dengan nilai densitas 423,7 kg/km2, sedangkan kepadatan stok terendah ada pada stasiun 3 dengan nilai densitas 281,39 kg/km2. Kepadatan stok menunjukan seberapa besar stok ikan yang tersedia di alam untuk dimanfaatkan. Stasiun 3 memiliki kepadatan stok yang rendah karena profil kedalaman pada lokasi tersebut tergolong perairan dalam sehingga kurang optimum bagi kehidupan ikan demersal dan beberapa jenis krustasea, oleh karena itu kepadatan stoknya rendah.

\section{KESIMPULAN DAN SARAN}

1) Alat tangkap dogol yang digunakan di stasiun 3 memiliki nilai laju tangkap terbesar yaitu sebesar 21,08 kg/jam, sedangkan nilai laju tangkap terendah terdapat pada alat tangkap dogol yang digunakan di stasiun 2 .

2) Kepadatan stok ikan demersal di perairan Pangandaran pada saat penelitian mencapai 423,70 $\mathrm{kg} / \mathrm{km}^{2}$ terdiri dari 15 famili dan 18 spesies, dengan famili paling dominan adalah famili Penaeidae.

\section{DAFTAR PUSTAKA}

Akbar H. 2013. Hubungan Tipe Dasar Perairan terhadap Distribusi Ikan Demersal di Perairan Pangkajene Sulawesi Selatan. Jurnal Teknologi Perikanan dan Kelautan, 4 (1): 31-39.

Cahya CN, Dadmuk, S, Dewi, S. 2016. Pengaruh Parameter Oseanografi terhadap Distribusi Ikan. Oseana, 41 (4):1-14.

Dewanti LP, Mahdiana I, Zidni I, Herawati H. 2018. Evaluasi Selektivitas dan Keramahan Lingkungan Alat Tangkap Dogol di Kabupaten Pangandaran Provinsi Jawa Barat. Jurnal Airaha, 7 (1): 030037.

Dewanti LP, Apriliani I M, Faizal I, Herawati H., Zidni, I. 2018. Perbandingan hasil dan laju tangkapan alat penangkap ikan di TPI Pangandaran. Akuatika Indonesia, 3(1), 54-59.

Fahmi, Yonvitner. 2016. Keanekaragaman Hayati dan Kepadatan Stok Ikan Demersal di Perairan Tambelan, Laut Natuna. Jurnal Ilmu dan Teknologi Kelautan Tropis, 8 (2): 503-516.

Fauzy RI. 2009. Analisis Perikanan Tangkap Pasca Tsunami di Pangandaran Kabupaten Ciamis, Jawa Barat. Skripsi. Fakultas Perikanan dan Ilmu Kelautan. Institut Pertanian Bogor. 
Firdaus M. 2010. Hasil Tangkapan dan Laju Tangkap Unit Perikanan Pukat Tarik, Tugu, dan Kelong. Makara, Teknologi, 14 (1):22-28.

Hakim, L. 2016. Cantrang: Masalah Dan Solusinya. In Seminar Nasional Riset Inovatif (Vol. 4).

Hidayat T, Nurulludin. 2017. Indeks Keanekaragaman Hayati Sumberdaya Ikan Demersal di Perairan Samudera Hindia Selatan Jawa. Jurnal Penelitian Perikanan Indonesia, 23 (2).

[KKP] Kementerian Kelautan dan Perikanan. 2015. Peraturan Menteri Kelautan dan Perikanan Republik Indonesia Nomor 2/PERMEN-KP/2015 tentang Larangan Penggunaan Alat Penangkapan Ikan Pukat Hela (trawls) dan Pukat Tarik (seine nets)di Wilayah Pengelolaan Perikanan Negara Republik Indonesia.

Nurhayati A, 2013. Analisis Potensi Lestari Perikanan Tangkap di Kawasan Pangandaran. Jurnal Akuatika, 4 (2): 195-209.

Pambuko DM, Jondri, Umbara RF. 2013. Identifikasi Kedalaman Laut (Bathymetry) berdasarkan Warna Permukaan Laut pada Citra Satelit mengggunakan Metode ANFIS. JMI. 9 (2): 167-178.

Pauly D. 1980. A new methodology for rapidly acquiring information on tropical fish stocks: growth, mortality and stock-recruitment relationships, P. Roedel and S. Saila (eds.) Stock assessment for tropical small-scale fisheries. International Center for Marine Resources Development, University of Rhode Island, Kingston. 154-172pp.

Priatna A, Wijopriono. 2011. Estimasi stok sumber daya ikan dengan metode hidroakustik di perairan Kabupaten Bengkalis. Jurnal Penelitian Perikanan Indonesia, 17(1):1-10.

Pujiyati S, Wijopriono W, Nahiswara M, Pasaribu BP, Jaya I, Manurung D. 2017. Estimasi hambur balik dasar perairan dan sumber daya ikan demersal menggunakan metode hidroakustik. Jurnal Penelitian Perikanan Indonesia, 13(2): 145-155.

Purbayanto A, Riyanto. 2005. Pengoperasian Pukat Udang pada Siang dan Malam Hari Pengaruhnya terhadap Hasil Tangkap Sampingan di Laut Arafura. Maritek 5 (1): 29-41.

Sparre P, Venema SC. 1998. Introduction to tropical fish stock assessment. Part 1. Manual. FAO Fisheries Technical Paper. No. 306.1, Rev. 2. Rome, FAO, 407 pp.

Sumiono B. 2017. Laju tangkap dan kepadatan stok ikan demersal di perairan Selat Malaka. Jurnal Penelitian Perikanan Indonesia, 8(1): 51-67. 